\title{
EXPLOTACIÓN Y CONSERVACIÓN DE LOS RECURSOS FORESTALES: LAS ORDENANZAS DE NÁJERA DE 1560
}

\author{
Isabel MARTÍNEZ NAVAS \\ Profesora Titular De Historia DEL DeRECHO y DE LAS INSTITUCIONES \\ UNIVERSIDAD DE LA RIOJA \\ isabel.mnavas@unirioja.es
}

SUMARIO: I. INTRODUCCIÓN. II. LAS ORDENANZAS DE NAJERA SOBRE GUARDA DE LOS MONTES DE 1560: GESTACIÓN. III. LAS ORDENANZAS DE NÁJERA SOBRE GUARDA DE LOS MONTES DE 1560: CONTENIDO.

RESUMEN: Las ordenanzas locales son una valiosa fuente de información en relación a diferentes aspectos de la organización de la vida en la localidad. Buena parte de ellas, contiene prescripciones atentas al equilibrio entre la explotación y la necesaria conservación de los montes. Las que aquí se analizan corresponden a la segunda mitad del siglo XVI y al ámbito de la ciudad de Nájera y su comarca.

PALABRAS CLAVE: Ordenanzas municipales, Nájera, Derecho local medieval y moderno, Historia del derecho mediambiental.

\section{USE AND CONSERVATION OF WOODS: THE 1560 NÁJERA ORDINANCES}

ABSTRACT: Municipal ordinances are a valuable source of information about various aspects of the organization of life in the locality. Many of them contain legal provisions related to the equilibrium between exploitation and the necessary preservation of tree covered lands (woods). This analysis explores ordinances from the second half of the 16th century in the city of Nájera and its land.

KEY WORDS: Municipal ordinances, Nájera, Medieval and Modern local administration, Medieval and Modern Law, Enviromental Law History.

\section{Introducción}

Un expediente conservado en el Archivo General de Simancas nos acerca el proceso de gestación de un ordenamiento local que tiene por finalidad regular la interacción de varios municipios de La Rioja Alta en el aprovechamiento y conservación de ciertos recursos forestales. Se trata de un 
conjunto documental no muy extenso, pero en el que se contiene el texto mismo de unas Ordenanzas redactadas en 1560 y otros documentos que permiten seguir el proceso de elaboración y la tramitación de su confirmación en el Consejo de Castilla. Resulta, de este modo, posible conocer el punto de partida, la situación que genera la necesidad de adoptar medidas proteccionistas, el alcance de las mismas y el de la intervención de los diferentes agentes que participan en la gestación del nuevo ordenamiento.

La edición y estudio de las ordenanzas antiguas de diferentes localidades ha venido ocupando desde hace años las páginas de publicaciones periódicas de ámbito regional o local, de prestigiosas publicaciones de diferentes especialidades históricas $\mathrm{y}$, asimismo, ha dado lugar a estudios monográficos y ediciones facsimilares de numerosos ordenamientos locales. No escapa a este interés por el ejercicio de la potestad auto normativa de los Concejos el territorio de la actual provincia de La Rioja, en el que se enmarca este trabajo, con el que me propongo dar a conocer unas ordenanzas muy breves, atentas a la regulación del aprovechamiento de los recursos forestales por los vecinos de la ciudad de Nájera y de sus aldeas y de otras localidades del entorno․

En los últimos años, son muy numerosos los estudios planteados, desde el ámbito de la historia ambiental, en los que el objeto central de análisis son algunos de estos ordenamientos locales, toda vez que proporcionan rica información sobre el estado de montes y bosques y su preservación, sobre la explotación en régimen comunal o privativo de ciertos términos, o acerca del aprovechamiento de los recursos hídricos en la zona ${ }^{2}$. Con todo, no han sido aún utilizadas suficientemente, apuntándose, como razones que permiten explicar que no se haya recurrido de forma habitual a las mismas, la idea extendida de que su contenido difiere poco de unos a otros ordenamientos, así como su carácter estático y la necesidad de recurrir a otras fuentes para conocer la efectividad de sus previsiones ${ }^{3}$. Ciertamente, las fuentes documentales que arrojan noticias precisas sobre la intervención humana en el paisaje, en particular en lo referente a las superficies arboladas, van más allá de las ordenanzas municipales ${ }^{4}$. Pero no cabe duda de que estas constituyen una fuente "de primera fila", proporcionándonos "valiosas noticias acerca de las modalidades de aprovechamiento de los montes, de los problemas ecológicos y sociales existentes en su entorno y de su propia composición florística" ${ }^{6}$ y erigiéndose en "auténticos programas de intervención" que "se

\footnotetext{
${ }^{1}$ A los primeros trabajos atentos a las Ordenanzas municipales de Logroño, han seguido otros sobre la propia capital de La Rioja y de localidades como Arnedo, Ezcaray o Navarrete.

2 Sobre el valor de estos ordenamientos locales, RAMOS SANTOS, J.M., "Ordenanzas de montes y conflictividad social en la Corona de Castilla: De la Baja Edad Media a la Edad Moderna”, en Salamanca. Revista de Estudios, 53 (2006), 35.

3 RODRÍGUEZ GRAJERA, A., "Las Ordenanzas locales como fuente para la Historia ambiental durante el Antiguo Régimen en Extremadura”, en Chronica Nova, 27 (2000), 168-170.

${ }^{4}$ Resultan de interés también los Libros de Actas de los Concejos, los de cuentas de los bienes de propios, los procesos que tienen su origen en los intereses encontrados de los vecinos de localidades próximas, etc. Sobre la utilidad de su empleo conjunto, como medio que permite corregir la imagen estática ofrecida por las ordenanzas y que proporciona una mejor comprensión de la problemática ligada al aprovechamiento forestal y los conflictos derivados del mismo, RAMOS SANTOS, J.M., "Fuentes historiográficas para el estudio e interpretación de los montes y sus aprovechamientos: su aplicación en Castilla y León (siglos XVI-XX)", en Investigaciones geográficas, 36 (2005), 43-44.

${ }^{5}$ CALONGE CANO, G., "Implicaciones biogeográficas de las Ordenanzas medievales de las comunidades de Cuéllar y Sepúlveda sobre un monte de pinos como elemento esencial de la vegetación autóctona”, en Cuadernos de la Sociedad Española de Ciencias Forestales, 16 (2003), 103.

${ }^{6}$ ALLUÉ-ANDRADE CAMACHO, M., "Aprovechamiento y conservación de los montes en la jurisdicción de la villa de Guadarrama (Madrid) durante la segunda mitad del siglo XVI”, 291..
} 
van reformando en relación con las nuevas necesidades que surgen y que obligan a ampliar las limitaciones en los aprovechamientos de los montes", de suerte que las ordenanzas adquieren, en esos supuestos, un carácter dinámico 7 . Por lo que se refiere a la singularidad de las ordenanzas, es claro que las cuestiones contempladas en las mismas y el modo en que se abordan, presentan una evidente similitud, toda vez que, tanto los aprovechamientos como las prácticas lesivas para el monte y también las medidas tendentes a procurar la recuperación de los montes esquilmados, son muy similares. No obstante, las circunstancias concretas determinadas por el propio paisaje forestal y por la densidad de la población que tiene acceso a los recursos del monte, determinará la puesta en marcha de medidas proteccionistas con mayor o menor celeridad y calado. Su carácter eminentemente casuístico justifica, así, el interés por el análisis individualizado de cada ordenamiento. El estudio de unas ordenanzas muy breves, como las formadas en Nájera en 1560, tiene el interés de aproximarnos a la estructura socioeconómica de la región y al peso que, en la misma, representan los recursos forestales y a la conflictividad derivada de su explotación por diferentes localidades del entorno. En lo que a la historia del derecho interesa, el estudio de las ordenanzas municipales proporciona información sobre el ejercicio de la potestad normativa de los Concejos y sobre la estructura y organización de los mismos. En las ordenanzas que aquí se analizan, puede percibirse también la traslación, a un municipio castellano, de las previsiones contenidas en la legislación general sobre montes.

\section{Las Ordenanzas de Nájera sobre guarda de los montes de 1560: gestación}

\section{II.1. El Concejo de Nájera en la mitad del siglo XVI}

Conocemos bien la estructura de gobierno de la ciudad de Nájera en la mitad del siglo $\mathrm{XVI}^{8}$. Desde 1465, Nájera formaba parte de los dominios de los Manrique, por donación efectuada por Enrique IV en favor del II conde de Treviño, en reconocimiento de la fidelidad mostrada por éste, Pedro Manrique, quien, a diferencia del resto de su linaje, había resuelto no abandonar al rey en su enfrentamiento con el infante don Alfonso. Esta fue la más relevante incorporación al patrimonio de su Casa por parte de Pedro Manrique, a quien el rey cedió Nájera, por juro de heredad, con sus castillos y fortalezas y todos los lugares de su tierra y jurisdicción, siéndole confirmada, en 1476 y en 1482, por los Reyes Católicos, al tiempo que se le otorgaba el título de duque de Nájera ${ }^{9}$. En lo tocante al gobierno de la ciudad, su dependencia del duque se tradujo en la inmediata sustitución de las autoridades concejiles anteriores por las designadas, en adelante, por el señor:

...os dejen y consientan libremente a vos -dispone Enrique $I V-$ y a los que, de vos, en los dichos oficios de la Justicia y de los otros oficios de la dicha Ciudad y su tierra, pusiereis en

\footnotetext{
7 RAMOS SANTOS, J.M., "Intervención humana y transformación de los paisajes forestales en la cuenca del Duero durante la Edad Moderna”, en Papeles de Geografía, 41-42 (2005), 209 y 216; RODRÍGUEZ GRAJERA, A., "Las Ordenanzas locales como fuente...", cit., 169.

${ }^{8}$ Los trabajos publicados por F.J. Goicolea Julián sobre el gobierno de diferentes localidades riojanas en el período medieval y en el tránsito a la Modernidad, nos acercan, en muchos casos, también a aquellos que ocuparon una posición destacada en la estructura del gobierno urbano, como se verá después.

9 MONTERO TEJADA, R.M., “Los señoríos de los Manrique en la baja Edad Media", en Espacio, Tiempo y Forma, Serie III, Historia Medieval, 7 (1994), 212.
} 
vuestro lugar, usarlos y ejercer, así en lo civil, como en lo criminal. Y cumplir y ejecutar, en ella y en su término, la mi Justicia. Y haber y llevar los derechos a ella pertenecientes ${ }^{10}$.

De este modo, los anteriores alcaldes, elegidos por la ciudad, fueron sustituidos por el doctor Alonso Hernández de la Peña, designado por el duque para ejercer con el título de corregidor, con carácter permanente, y contando con el auxilio de un teniente ${ }^{11}$. Los restantes oficios regidores, procurador general, letrado, etc. - serían, asimismo, provistos por los sucesivos duques de Nájera $^{12}$, registrándose, en 1540, la única novedad reseñable: la introducción en Nájera del oficio de diputado, presente, desde el final del reinado de los Reyes Católicos, en los gobiernos municipales ${ }^{13}$.

En el tiempo en el que se impulsa la formación de las Ordenanzas de montes, al frente del gobierno de la ciudad se encontraban el corregidor Peña Velázquez, los regidores Rodrigo Ximénez de Cabredo y Hernando Aguado y, como diputados, Antonio de León, Martín de Vergara, Gonzalo García, Pedro de Rodezno y los doctores Mendoza y Cañas ${ }^{14}$. Estos, junto con el procurador general de la ciudad, Sebastián de Vergara, van a ser algunos de los protagonistas de la gestión del expediente conducente a la adopción de medidas eficaces para la preservación del monte. Los otros protagonistas serán los vecinos de la ciudad, por un lado, y, de otra parte, el rey y el Consejo de Castilla. Estos últimos intervendrán en dos momentos cruciales de este proceso: en su comienzo, respaldando la pretensión de la ciudad de dotarse de nuevos instrumentos para la conservación de sus términos; y, a su conclusión, estudiando, matizando en lo que entienden preciso, y confirmando las ordenanzas aprobadas

\footnotetext{
${ }^{10}$ AHN, Nobleza, Osuna, 296, 1, f. 103.

${ }^{11}$ El primer corregidor designado por Pedro Manrique lo fue en 1478, pero la presencia de corregidores no fue permanente hasta tiempo después. Sería entonces - finales de la década de los ochenta- cuando el duque habría decidido sustituir a los anteriores alcaldes ordinarios por un representante del poder señorial permanente, al que se designará como corregidor. GOICOLEA JULÍAN, F.J., "La ciudad de Nájera en la Baja Edad Media como espacio de poder político y social”, en DE LA IGLESIA DUARATE, J.I. y MARTÍN RODRÍGUEZ, J.L., Los espacios de poder en la España medieval: XII Semana de Estudios Medievales, Nájera, del 30 de julio al 3 de agosto de 2001, 3 vols., Logroño, Instituto de Estudios Riojanos, 2002, 173-174.

12 En 1540 eran cuatro los regidores y diputados, designándose también un letrado, un procurador, un escribano de cámara, dos alcaldes de Hermandad, un bolsero, dos cuadrilleros, dos fieles de la balanza, dos fieles del vino, dos fieles de la carnicería, dos veedores de los paños, dos veedores de los zapatos, dos veedores del campo, cuatro jurados, siete custieros, dos portazgueros y al mayordomo de San Lázaro. En este sentido, GOICOLEA JULIÁN, F.J., "La ciudad de Nájera en el tránsito de la Edad Media a la Moderna: El concejo, el señor y la sociedad política ciudadana”, en Hispania, LX/2, núm. 205 (2000), 449.

13 Según GOICOLEA JULIÁN, Nájera habría sido el último núcleo urbano de La Rioja en incorporar a los diputados en el Concejo, "Concejos urbanos en La Rioja Alta a fines del Medievo: Aspectos institucionales y políticos”, en Historia, Instituciones, Documentos, 26 (1999), 233-254. Apunta este autor que, desde 1540, fueron cuatro los diputados najerinos -correspondiendo ejercer ese empleo a los cuatro regidores salientes-, habiéndose incrementando en dos diputados más, a partir de 1557, a solicitud del propio Concejo, "La ciudad de Nájera en el tránsito de la Edad Media a la Moderna...”, cit., 449. Por ese tiempo, se habrían reducido, en igual número, las regidurías.

14 AGS, Consejo Real de Castilla, 355, exp. 7. Buena parte de ellos son mencionados por GOICOLEA, quien los identifica al frente de algunos de los oficios concejiles, en diferentes momentos, desde 1540 en adelante, El gobierno urbano en La Rioja en época medieval e inicios de la Edad Moderna (s. XIII-mediados del XVI), Logroño, Instituto de Estudios Riojanos, 2004, 123-124.
} 
por el Concejo najerino. Por su parte, los vecinos tendrán también un destacado papel en la decisión acerca del contenido de las nuevas ordenanzas.

\section{II.2. El deterioro del monte y las medidas proteccionistas}

La razón de ser de la elaboración de unas nuevas ordenanzas -concisas y bien centradas en el objetivo perseguido con las mismas, como después se podrá ver-, la encontramos en la preocupación de las autoridades najerinas por el calamitoso estado a que había llegado el conocido como monte de Matarredo, sobre el que, tanto la ciudad, como sus aldeas y otras localidades próximas, tenían reconocidos diferentes de aprovechamiento de leña y pastos.

Matarredo, enclavado en el más amplio término de La Verde, había formado parte, según apunta Narciso Hergueta, de los dominios del Monasterio de Santa María de Nájera ${ }^{15}$, constituyéndose después en bien público concejil y habiendo sido -a decir de los vecinos de esta ciudad- "usurpado por el duque", quien habría talado y cortado en Matarredo, vedado la caza en el mismo y sancionado gravemente a los vecinos que buscaban abrigo para sus ganados en el dicho monte ${ }^{16}$.

La preocupación por el deterioro del monte habría estado presente, en mayor o menor medida, en las poblaciones rurales y entre los grandes propietarios, desde siempre. La necesidad de ordenar la intervención humana sobre montes y bosques se pone de manifiesto, así, en los más antiguos textos forales, en los que se contemplan, junto a la donación, en su caso, de espacios forestales, los aprovechamientos atribuidos a los vecinos y los derechos que percibe la localidad en concepto de "montazgo", esto es, por permitir a los forasteros el acceso a los pastos ${ }^{17}$. Más adelante, la sobreexplotación asociada al crecimiento demográfico de la sociedad medieval y el incremento de las superficies cultivadas generarán nuevas tensiones desde el final del siglo $\mathrm{XV}^{18}$. Con dos consecuencias: Por una parte, serán frecuentes los conflictos entre localidades, o entre los concejos y los vecinos, que se resolverán tras un largo periplo judicial o, en muchos casos, con la formalización de la oportuna concordia que ordene de común acuerdo los límites de la intervención de unos y

\footnotetext{
${ }^{15}$ HERGUETA, N., "Rioja antigua. Retazos históricos de la familia Manso de Zúñiga. Torremontalbo, Somalo y Cenicero", en Academia Heráldica, t. II, febrero de 1907, 17-18.

${ }^{16}$ Este sería uno más de los agravios que los najerinos dirán haber sufrido por parte del duque de Nájera y que les llevarán a levantarse contra su señor en el tiempo en que se extiende por Castilla la revuelta de las Comunidades. Sofocado el movimiento anti señorial en Nájera por parte de Antonio Manrique, II duque de Nájera y virrey de Navarra, retornarán a la ciudad el corregidor y su teniente, designados por el duque, quien participará asimismo en el nombramiento de los restantes oficiales del Concejo. El Memorial presentado por dos representantes de la ciudad de Nájera, en 1518, solicitando la intervención real y la reparación de los agravios relacionados en el mismo, en AGS, Cámara de Castilla, Memoriales, leg. 130, doc. 61. Citado por GOICOLEA JULIÁN, J., "La ciudad de Nájera en el tránsito de la Edad Media a la Moderna”, cit., 439-443.

${ }_{17}$ CRUZ AGUILAR, E., La destrucción de los montes (Claves histórico-jurídicas), Madrid, 1994, 39-40.

${ }^{18}$ LUCHÍA, C., "Porque los montes de esta villa se conserven, e no se disipen como al presente están: La regulación de los recursos forestales en la Corona de Castilla (siglos XIV-XVI)", en Espacio, Tiempo y Forma, Serie III. Historia Medieval, 33 (2020), 306.
} 
$\operatorname{otros}^{19}$. De otro lado, se intensificará la actividad normativa, con la vista puesta en procurar una completa y eficaz regulación de los montes ${ }^{20}$.

La riqueza forestal constituye una relevante fuente de ingresos para las poblaciones -venta de leña, arrendamiento de pastos, etc. -, al tiempo que proporciona recursos a los vecinos -leña, carbón, madera, o alimento para el ganado-, de suerte que todos ellos están interesados en una explotación racional del monte ${ }^{21}$. Se abrirá paso así una regulación proteccionista con la que se quiere paliar la merma de la superficie forestal, que se percibe como una amenaza para el modelo socioeconómico del Antiguo Régimen ${ }^{22}$. Esa inquietud por la conservación del monte se pondrá de manifiesto reiteradamente por las Cortes y llevará a la Corona a impulsar medidas de conservación y acrecentamiento de los montes ${ }^{23}$. En 1496, habiéndose advertido los problemas derivados de la tala descontrolada, se dispuso la prohibición general de talar y cortar, a la que seguían la excepción representada por las extensas superficies forestales y la ordenación en todo caso de los aprovechamientos de leña, pastos y abrigo para el ganado ${ }^{24}$. A las medidas proteccionistas se sumaron, en 1518, las tendentes a procurar el incremento de la superficie forestal ${ }^{25}$, en cuyo origen se encontraba una petición de Cortes abogando por que se ordenase plantar montes y guardar los ya

19 A la conflictividad entre Concejos, como fuente que permite conocer el contenido de las respectivas ordenanzas municipales y su efectividad, se ha referido RAMOS SANTOS, J.M"., "Fuentes historiográficas para el estudio e interpretación de los montes...", cit., 46. Se ha servido de la amplia documentación conservada en el Archivo de la Real Chancillería de Valladolid para abordar el estudio de las relaciones del hombre con el medio forestal en espacios concretos de Castilla. Así, en "Aprovechamientos forestales, ordenanzas de montes y conflictividad social en el norte de Palencia en la Edad Moderna (siglos XVII-XVIII)", en Polígonos. Revista de Geografía, 17 (2007), 133-153.

${ }^{20}$ Como advierte LUCHÍA, se trata de un fenómeno extendido por las diferentes regiones europeas, en las que proliferan ordenamientos sobre montes y bosques de carácter proteccionista, "Porque los montes de esta villa...", cit., 306.

${ }^{21}$ RAMOS SANTOS, J.M., "Fuentes historiográficas para el estudio e interpretación de los montes...", cit., 44. 22 RODRÍGUEZ GRAJERA, A., "Las Ordenanzas locales como fuente...”, cit.,177; Por su parte, RAMOS SANTOS, recuerda que, durante el siglo XVI, en ciertas zonas de Castilla y León se habría extendido la deforestación, provocándose la desaparición del monte, tal como señalan algunos de los viajeros extranjeros que refieren la carestía de la leña en determinados lugares y la ausencia de montes, "Fuentes historiográficas para el estudio e interpretación de los montes...", cit., 57. Sobre la recuperación del monte y los resultados de las medidas proteccionistas, RAMOS SANTOS, ibidem, 58 y LUCHÍA, para quien es manifiesta la permanencia e incluso acrecentamiento del bosque en ciertas áreas, lo que contrasta con cierta imagen de retroceso absoluto del espacio forestal en Castilla como consecuencia de la transformación del paisaje castellano, "Porque los montes de esta villa...", cit., 307.

${ }^{23}$ Como señala CRUZ AGUILAR, la preocupación por el cuidado de los montes será una constante en las Cortes castellanas, revelando, en algunos casos, la reiteración de los incumplimientos y, en los más de ellos, tan sólo la necesidad de recordar la norma, La destrucción de los montes..., cit., 65. Por su parte, RAMOS SANTOS se refiere al "empeño de la Monarquía en la conservación y extensión de las superficies forestales", "Ordenanzas de Montes y conflictividad social en la Corona de Castilla”, en Salamanca. Revista de Estudios, 53 (2006), 39.

${ }^{24}$ Nueva Recopilación, VII, 7, 7.

25 Ibídem, VII, 7, 15. Se ha apuntado que "el régimen medieval de montes se caracteriza por atender a los problemas de pertenencia y aprovechamiento. En cambio, el régimen moderno se orienta hacia la conservación y el incremento". En este sentido, GIBERT, R., “Ordenanzas Reales de Montes en Castilla (1496-1803), en Actas del II Symposium de Historia de la Administración, Madrid, 1971, 312-317. 
existentes y por la observancia de las ordenanzas municipales ${ }^{26}$. La buena acogida dispensada a la petición formulada por los procuradores castellanos se tradujo en tres medidas destinadas, respectivamente, a promover replantaciones y nuevos plantíos, a garantizar el cumplimiento de la legislación general y de los ordenamientos locales y, finalmente, a promover la elaboración de estas ordenanzas sobre montes y plantíos, allá donde no se contase con las mismas ${ }^{27}$.

Por lo que se refiere a esta última previsión, no es posible precisar su alcance efectivo. En muchos casos, las ciudades y villas castellanas contarían ya con unas ordenanzas capaces de dar satisfacción a esa necesidad de ordenar la relación del Concejo, de sus vecinos y de los forasteros, por lo que podrían no sentirse compelidos a dotarse de "las ordenanzas que vosotros viereis que convengan”. En otros, la ausencia de regulación previa, o la apreciación por el Concejo de la necesidad de revisar la anterior, habrían favorecido el desarrollo de nuevas ordenanzas. Con todo, también esas nuevas ordenanzas habrían precisado más adelante nuevas actualizaciones, como también la propia legislación general sobre los montes, que, en la década de los setenta, continuaba preocupando a Felipe II, quien expresaba "su temor de que los sucesores iban a quejarse de encontrarlos consumidos" 28 . Esa preocupación por la destrucción de la superficie forestal estará presente entre los vecinos de Nájera y su comarca por ese tiempo.

\section{II.3. Las Ordenanzas de montes de Nájera de 1560}

$\mathrm{Si}$, en 1518, los vecinos -como antes apunté- parecían inquietos por su relación con los cercanos "monte y dehesa de Matarredo y monte y dehesa de Dulçeda" 29, cuatro décadas después el estado de degradación del primero, habría llevado, de nuevo, a plantear la necesidad de adoptar drásticas y urgentes medidas para su preservación ${ }^{30}$. El lamentable estado en que se encontraba en ese tiempo el monte de Matarredo debió ser bien descrito por el procurador najerano, Sebastián de Vergara -quien se habría dirigido al rey y al Consejo de Castilla, solicitando una urgente intervención para procurar la guarda y conservación del monte-, toda vez que la Real provisión de $1^{\circ}$ de junio de 1560 , por la que se da respuesta a la petición de la ciudad, incluía una prolija descripción del estado de Matarredo:

\footnotetext{
${ }^{26}$ La petición fue formulada por los procuradores en las Cortes de Valladolid de 1518, Cortes de los Antiguos Reinos de León y de Castilla, publicadas por la Real Academia de la Historia, Madrid, 1882, IV, 272-273.

27 Sobre la génesis, el contenido de las dos redacciones conocidas de la Pragmática de 21 de mayo de 1518 y los efectos de la misma, GIBERT, R., "Ordenanzas Reales de Montes en Castilla...”, cit., 317.

${ }^{28}$ En este sentido, en la Instrucción dirigida al presidente del Consejo de Castilla, Diego de Covarrubias, según apunta GIBERT, R., ibídem.

${ }^{29}$ GOICOLEA JULIÁN, J., "La ciudad de Nájera en el tránsito de la Edad Media a la Moderna...”, cit., 440.

30 Las noticias acerca de la formación de nuevas ordenanzas proceden exclusivamente del expediente conservado en AGS, Consejo Real de Castilla, 355, exp. 7, ya que, lamentablemente, en el Archivo Municipal de Nájera, no se han conservado las actas de las sesiones del Concejo para el período comprendido entre los años treinta del siglo XVI y avanzado el siglo XVIII. Al mencionado expediente corresponden, por tanto, la totalidad de las referencias documentales incluidas a continuación, por lo que no se incluyen más notas a pie de página que las estrictamente indispensables.
} 
...un monte de encinas, que se dice Matarredo, el cual solía estar muy poblado y espeso de encinas, caudales y de matas de las dichas encinas, en que se hacían y crecían más encinas, el cual dicho monte, estando criado, como solía, era de grandísima utilidad para la dicha ciudad y para algunos lugares de su tierra y jurisdicción que tenían aprovechamiento de pacer con sus ganados en él $[\ldots]$ y con ser muy pequeñas las penas antiguas que se solían llevar a los que cortaban pies o rama de encina en el dicho monte, se había cortado en él con tanta libertad que eran muy pocas las encinas que habían quedado y de aquéllas, las más, estaban desmochadas y el suelo ralo, sin haber ninguna mata...

Que se había llegado a una situación prácticamente insostenible era conocido por todos los que tenían relación con el citado paraje. Por esa razón, en nombre de la ciudad de Nájera, su procurador general, no había dudado en instar que se proveyese remedio para el mismo:

...y convenía mucho a esa dicha ciudad y vecinos de ella y de los lugares que tenían aprovechamiento en el dicho monte, que se diese alguna orden cómo el monte volviese a renacer y crecer...

Tampoco escapó, desde luego, a la atención del Consejo, que convino en la necesidad de redactar nuevas ordenanzas de conformidad con la Pragmática de 1518, cuyo tenor se insertó en la Real provisión de Felipe II, de $1^{\circ}$ de junio de 1560, por la que se respondía a la instancia de Sebastián de Vergara.

...se diese carta y provisión, insertando la Pragmática de los Montes - habia solicitado este último, en nombre de la ciudad-, para que, conforme a ella, se hiciesen las Ordenanzas que conviniesen y fuesen necesarias para la conservación y restitución del dicho monte.

Así las cosas, el Ayuntamiento de Nájera, reunido el 15 de junio de 1560, recibió, con el acatamiento debido, la Real provisión fechada a comienzos del mismo mes. De forma inmediata, el corregidor, Peña Velázquez, instó al procurador general a trasladarle la información precisa para dar cumplimiento a la disposición real. Y por parte de éste, se requirió, en efecto, el cumplimiento de lo en ella dispuesto y se hizo entrega al corregidor de un escrito que contenía las preguntas, por las que serían interrogados los testigos necesarios, con el fin de recabar información suficiente sobre diferentes extremos relacionados con el monte de Matarredo.

... por las preguntas siguientes sean preguntados los testigos que, por parte del Concejo, Justicia y regidores de esta ciudad son o serán presentados sobre la información que pretenden dar sobre el corte del monte de Matarredo de esta ciudad ${ }^{31}$.

Las cuestiones acerca de las que pretendía recabarse información iban desde la titularidad del dicho monte y los derechos que sobre el mismo podían tener los vecinos de otros pueblos próximos a la ciudad de Nájera, hasta la oportunidad de establecer nuevas y restrictivas ordenanzas que regulasen el aprovechamiento del monte de Matarredo. No se trataba, desde luego, de un interrogatorio aséptico. Bien al contrario, la formulación de las preguntas orientaba de forma indudable las respuestas que podrían recabarse. Así, lejos de formular las cuestiones de manera abierta, obteniéndose de los potenciales testigos un relato acerca del estado en que se encontraba el

${ }^{31}$ Se trata de un escrito en el que se contienen siete preguntas por las que debía tomarse información a los testigos que se presentasen. 
monte y sobre las medidas que, a juicio de los mismos, podrían resultar adecuadas para tratar de revertir la situación, las propias preguntas aparecían plagadas de expresiones que inducían al testigo a manifestarse en el mismo sentido ${ }^{32}$, o incluían la respuesta que se esperaba en relación a la necesidad de dotarse de nuevas ordenanzas:

Item, si saben -rezaba la tercera de las preguntas- que, porque esta ciudad y los vecinos de Huércanos, Somalo, Uruñuela y Cenicero y Tricio, tienen derecho de cortar en el dicho monte de Matarredo con ciertas penas. Y, por ser las penas pequeñas [...], de algunos años a esta parte, han cortado y talado de tal manera el dicho monte, por píe y por rama, y casi lo han dejado inútil y sin provecho, por estar tan talado y cortado como está.

Item - continuaba la cuarta pregunta-, si saben que, por la dicha razón contenida en la pregunta antes de ésta, conviene y es necesario que, para guarda y conservación del dicho monte y para que no se acabe de talar y cortar y sacar de cuajo, que se ordene y hagan ordenanzas de nuevo, con mayores penas, para que se guarde y conserve el dicho monte, por ser, como es, útil y necesario para el pasto y abrigo de los ganados de esta ciudad y su tierra, porque si no se hacen ordenanzas graves, se acabaráde cortar y talar en poco tiempo.

Item, si saben que, viendo esta ciudad la gran desolación que pasaba en el dicho monte, hizo ordenanzas para los vecinos de esta ciudad y de su barrio de Tricio y Cenicero [...] y tampoco, aunque se ha usado, no ha sido bastante remedio para que el dicho monte se guarde $[\ldots]$ y así conviene que para todos haya ordenanzas con muchas penas, porque se guarde por la necesidad que hay del dicho monte.

Esta suerte de información pública resultó, además, bastante limitada. Del expediente conservado se desprende que fueron siete los testigos interrogados entre los meses de junio y agosto $^{33}$. La información dio cabida, no obstante, a representantes de los diferentes municipios que tenían derechos de explotación en Matarredo. Declararon, así, sendos vecinos de Nájera, Uruñuela, Huércanos y de la aldea o barrio de Tricio. Junto a estos cuatro, fueron llamados tres vecinos de Somalo, quizá por tratarse de la población que, por su proximidad al monte, se había revelado como aquella en la que los vecinos podían constituir un mayor peligro para su preservación. De hecho, mucho tiempo atrás habían sostenido un largo conflicto por la titularidad con el Monasterio de Santa María de Nájera ${ }^{34}$.

En todo caso, los testimonios que forman parte del expediente convienen en la respuesta a la que conducían las preguntas formuladas: afirman, así, que eran conscientes de que el estado de sobreexplotación del monte de Matarredo había llegado a un punto en el que se temía la destrucción del mismo. Y, asimismo, en que, para remediarlo, era necesario el desarrollo de una nueva regulación que contemplase iguales sanciones para los infractores, con independencia de si éstos eran vecinos de Nájera y sus aldeas, o de si se trataba de vecinos de las poblaciones del entorno. Esto es, ni más ni menos de lo que se esperaba: la confirmación de la inquietante situación de Matarredo y la apuesta

\footnotetext{
32 Acerca del estado en que se encontraba el monte de Matarredo, las preguntas incluían referencias a que "se acabará de cortar y talar en poco tiempo", a que "lo han destruido y destruyen escondidamente", a "que hay tanta falta de montes en esta tierra", o, abiertamente, a "la gran desolación que pasaba en el dicho monte".

${ }^{33}$ El primero de los testigos declaró el 27 de junio de 1560 y el último fue interrogado el 17 de agosto, según el expediente conservado en AGS, Consejo Real de Castilla, 355, exp. 7.

${ }^{34}$ Sobre esto último, HERGUETA, N., "Rioja antigua. Retazos históricos de la familia Manso de Zúñiga...", cit., 17-18.
} 
decidida por una nueva regulación que contemplase medidas eficaces para su recuperación y conservación en adelante.

En el mes de octubre de 1560, volvió a reunirse el Ayuntamiento najerino y se dio el siguiente paso: la designación de los vecinos de la ciudad de Nájera que tomarían parte en la formación de las nuevas ordenanzas, de conformidad con las previsiones de la legislación general de montes.

... para hacer las ordenanzas de que en la Provisión real se hace mención -se refieren a la fechada el $1^{\circ}$ de junio de 1560-, que fuesen llamados Alonso Rubio y Alonso de Yanguas, el doctor Juan Alonso, Pero Hernández de Nieva, Pero de Cerezo, Diego de Logroño, Diego Pérez de Calahorra, Sancho Martín, Juan de Solano, Íñigo Cordero el viejo, Fernán de Hontaneda, Diego de Páganos, Hernán López [...] para que, todos juntos, vean y confieran, y ordenen la orden y forma que mejor sea para poder hacer que se guarde y conserve el dicho monte y los que se plantaren de nuevo y se hagan para ello las ordenanzas necesarias como por la Majestad Real es mandado.

No conocemos cómo se llevó a cabo esa selección, si bien se indica que se trató de "personas hábiles y de buen entendimiento y de los que tienen experiencia de las cosas de la dicha ciudad y república de ella". Lo que sí consta es que se trató, en todos los casos, de vecinos de la ciudad de Nájera y que éstos, conjuntamente con el corregidor y los regidores, analizaron la situación "por vista de ojos" y tuvieron, asimismo, presente la información recabada en los meses precedentes. Dos semanas después de ser designados, los comisionados para la formación de las ordenanzas debían haber concluido su misión, de suerte que, reunidos de nuevo con la Justicia y Regimiento, en las casas del Ayuntamiento de Nájera, el 20 de octubre de 1560, "confirieron y platicaron" acerca de los diferentes extremos que debían contemplarse en las nuevas ordenanzas y, de forma unánime, adoptaron el correspondiente acuerdo, pregonándose las ordenanzas unos días más tarde.

... en la dicha ciudad de Nájera, a treinta y un días del mes de octubre del dicho año de mil y quinientos y sesenta años, en la plaza de San Juan, frontero las casas del Consistorio de la dicha ciudad, estando presentes los dichos señores Justicia y Ayuntamiento y gran copia de vecinos de la dicha ciudad, pregonaron públicamente las dichas ordenanzas, como en ellas se contiene, a altas voces, que todos lo podían oír. Testigos que fueron presentes ...

El expediente concluía un año más tarde, cuando, vistas las Ordenanzas de los montes de Nájera, el Consejo de Castilla ordenó su confirmación, el 15 de octubre de 1561.

\section{Las Ordenanzas de Nájera sobre guarda de los montes de 1560: contenido}

Las Ordenanzas confirmadas por el Consejo de Castilla constan de tan sólo ocho capítulos en los que se abordan los diferentes extremos contemplados en la Real provisión de $1^{\circ}$ de junio de 1560. A saber: la necesidad de revertir la insostenible situación a la que había llegado el monte de Matarredo, la conveniencia de incrementar la limitada superficie forestal de Nájera y su entorno y, finalmente, la de formar ordenanzas atentas a la guarda y conservación del mencionado monte y de las nuevas plantaciones.

El primero de los objetivos consistía, pues, en adoptar las medidas necesarias para procurar la repoblación de un espacio que había resultado esquilmado tras años de sobreexplotación por parte 
de aquellos que tenían reconocidos derechos sobre el mismo. Un mal común, que ya contemplaba la Pragmática de los montes de 1518 y al que prestaba atención conjuntamente con la que parecía entonces la actuación más relevante -la extensión del monte comunal-, disponiendo que unos y otros, los viejos y los nuevos montes, debían gestionarse teniendo presentes los intereses inmediatos y futuros de los Concejos y de sus vecinos. De acuerdo con estas previsiones -que fueron sobrecartadas en la Real provisión de $1^{\circ}$ de junio de 1560-, las ordenanzas elaboradas por la ciudad de Nájera contemplaron, en primer término, la situación del monte de Matarredo, describiendo el nivel de destrucción que se había alcanzado en el mismo. Se convenía, no obstante, que, el paraje sobre el que se debía actuar, aunque gravemente destruido, presentaba posibilidades de recuperarse - "aunque está talado, quedaron raíces en él"-, de suerte que debían adoptarse medidas de protección que garantizasen la repoblación. El capítulo primero de las ordenanzas preveía, en este sentido, de una parte, que no se cortase, ni sacase de cuajo en adelante en el dicho monte y, de otro lado, que se plantase la extensa superficie más dañada, en la que no había árboles ni habían quedado raíces de los mismos. Sobre la repoblación de las zonas despobladas, la ordenanza tercera, disponía que se debían romper, arar y sembrar de encina de bellota, con la vista puesta en que resulte poblado como el resto del monte. La decisión de extender la superficie del encinar respondía, sin duda, a la voluntad de contar con un monte bajo, capaz de proporcionar, en su momento, pasto y leña a las poblaciones de su entorno.

La segunda línea de actuación pasaba por la identificación de otros términos, que presentasen unas condiciones adecuadas para su plantación. La finalidad era, claro está, ampliar la extensión de la superficie forestal, pues hay sobra de pastos y falta de montes en la comarca de Nájera. Así, los comisionados para formar las ordenanzas, procedieron a evaluar-como antes apunté- los términos sobre los que se podía actuar y, de común acuerdo, convinieron en que el conocido como término de La Verde, con una extensión de más de 25.000 fanegas de tierra, podía resultar útil a los efectos que se buscaban. Se trataba de un término que, en su práctica totalidad, estaba por romper. Realizada la oportuna inspección ocular, se convino en la bondad de que se sembrase de bellota una superficie de hasta 1.800 fanegas de tierra, correspondientes a un paraje cuyos límites quedaron precisados en el capítulo cinco de las Ordenanzas de 1560. Esa tierra era considerada como la más aparejada para poderse plantar $y$ criar el dicho monte.

Efectuadas las nuevas plantaciones, tanto en el monte de Matarredo como en La Verde, era preciso protegerlas. Con esta finalidad, el capítulo tercero de las ordenanzas dispuso la suspensión, por espacio de diez años, del derecho de pastos en Matarredo. En relación a los nuevos plantíos en el término de La Verde, la previsión fue la misma: prohibir la entrada de ganados en las nuevas plantaciones durante una década. Y no sólo los particulares, los vecinos, verían restringidos sus derechos de corta y pastos. El propio Concejo de Nájera debió asumir que, por espacio de los siguientes diez años, no podría obtener las rentas procedentes del arrendamiento de pastos en los períodos habilitados, anualmente, para su aprovechamiento. En este sentido, el capítulo cuarto de las Ordenanzas de 1560, precisaba que, transcurrido el tiempo necesario para que se repoblase el monte, la ciudad debería guardar su derecho antiguo, como hasta ahora.

A las limitaciones señaladas se añadió, claro está, la oportuna previsión de las sanciones que correspondería imponer a los infractores. De este modo, los capítulos dos y tres de las Ordenanzas, fijaron la cuantía de las penas pecuniarias en las que incurrirían los vecinos y forasteros que fuesen en contra de las medidas proteccionistas adoptadas por la ciudad. Las nuevas penas supusieron un agravamiento considerablemente de las previamente contempladas por la ciudad, adecuándose así a lo manifestado en la información de testigos, en la que, la totalidad de los declarantes apostaron por la imposición de penas más graves y, fundamentalmente, porque fuesen iguales para todos. Este era, 
sin duda, el punto más polémico. De la mencionada información se desprendía que, a la vista de la degradación que estaba experimentando el monte de Matarredo, el Concejo de Nájera había formado unas ordenanzas en las que se contemplaban penas para los infractores que iban desde los seiscientos hasta los sesenta maravedíes, que debían abonar los vecinos de Nájera y de sus aldeas, por la corta por píe o por rama, respectivamente. No tenemos noticia acerca de cuándo se habría adoptado esa decisión, pero sí parece que las mencionadas Ordenanzas habrían estado en vigor, siendo ejecutadas contra algunos vecinos. Sin embargo, a decir de los declarantes, no habrían bastado para contener la progresiva degradación del monte de Matarredo. El problema principal, según todos los encuestados, estribaba en que no se dispensaba el mismo tratamiento a los vecinos de las localidades de Huércanos, Somalo y Uruñuela, siendo estos los que, por su proximidad de Matarredo y, fundamentalmente, por la cortedad de las penas en que incurrían aquellos que tenían derecho de cortar, con pena -sesenta maravedíes por píe y cuatro maravedíes por rama-, habrían contribuido decisivamente al esquilmo del monte. La solución pasaba, pues, por el establecimiento de un régimen sancionador más severo, que pudiese resultar, en efecto, disuasorio.

... conviene y es necesario que, para guardar y conservar el monte y que no se acabe de talar y sacar de cuajo, que se hagan ordenanzas iguales para todos, con penas mucho más graves, para que se guarde y conserve el dicho monte. Que, si no se hiciesen Ordenanzas con grandes penas, está claro que se acabará de cortar y talar el dicho monte, como lo han hecho los años pasados y en el presente 35 .

Las Ordenanzas de 1560 dispusieron, así, penas actualizadas, que alcanzaban por igual a todos, ya fuesen vecinos de Nájera y de sus aldeas, o de fuera de estas localidades y que se aplicarían, por mitad, para la ciudad y la otra mitad, para el denunciador y el juez que lo sentenciare. Las prácticas perseguidas fueron, de una parte, la corta y tala en Matarredo, estipulándose sanciones de mil maravedíes de pena para cualquier persona que cortase o sacase de cuajo, de aqui adelante una encina grande o pequeña y de quinientos maravedíes al que hubiese cortado por rama, entendiéndose automáticamente incursos en dichas penas, que podrían ejecutarse en sus personas y bienes. Las anteriores previsiones se referían a infracciones cometidas durante el día, en tanto, la segunda de las Ordenanzas, preveía que, en los supuestos en que se hubiere aprovechado la noche, la pena resultaría doblada, incrementándose, también, la cuantía de esas penas en los supuestos de reincidencia: la segunda vez, doblada; y la tercera y rebeldía, doblada y esté dos meses en la cárcel. Esta última previsión relativa a la inclusión de penas no pecuniarias, fue suprimida, no obstante, en la revisión efectuada por el Consejo de Castilla.

Por otra parte, las penas que debían acompañar a la entrada fraudulenta de ganado en los términos de La Verde y Matarredo, serían ahora las mismas tanto si se trataba de un vecino de la dicha ciudad, ni de fuera parte, abora tenga derecho de pacer en él, o no lo tenga. La entrada de ganado estaba absolutamente vedada por espacio de diez años, tanto de día como de noche, incurriéndose en penas de mil maravedíes por rebaño, a lo que debería sumarse la satisfacción del daño causado. Las propias Ordenanzas declaraban que se consideraría rebaño el formado por diez cabezas de ganado, estipulándose, para el caso de que no se alcanzase ese número, que la sanción prevista sería de un real por cabeza de ganado menor y de cuatro reales por cabeza de ganado mayor. Al igual que en relación

\footnotetext{
35 Declaración de Antón de la Ribera, vecino de Uruñuela, el 27 de junio de 1560. En similares términos, los otros testigos: "que para que esto se guarde, se hagan ordenanzas graves y con grandes penas, que sean iguales para todos"; "que se ordene y hagan ordenanzas con grandes y graves penas. Y, si fuera posible, pena corporal. Que sean iguales para todos los que tienen derecho de cortar en el dicho monte"; "que se ordenen y hagan ordenanzas con muy mayores penas, iguales para todos”, etc.
} 
a la tala, se contemplaban penas dobladas si la introducción del ganado se produjese al abrigo de la noche. Inicialmente, también en este punto, el Concejo de Nájera y los comisionados encargados de la elaboración de las Ordenanzas de 1560, previeron sanciones no pecuniarias para los que incurriesen en rebeldía -en este caso, se apuntaba que el infractor sería traído a la vergüenza públicamente por las calles públicas de esta ciudad-, siendo éstas suprimidas en la revisión realizada por el Consejo en el tiempo de su confirmación.

Las Ordenanzas de 1560 tuvieron presente, asimismo, otro de los problemas puesto de manifiesto en la información de testigos: la dificultad para aprehender a los infractores, a los que no se podía prendar de vista, sino de alcance. Para resolverlo, el capítulo séptimo de las Ordenanzas, contempló expresamente la posibilidad de que bastase el juramento del guarda del campo y, asimismo, que en caso de que estos no lo hubiesen visto, se considerase prueba suficiente de la infracción la declaración de un testigo.

Finalmente, se sentó con claridad -tal como se había previsto en la Real provisión de $1^{\circ}$ de junio de 1560 - que, transcurridos los diez años previstos en las Ordenanzas, el Concejo podría volver a arrendar los pastos, desde el día de San Miguel de septiembre, hasta el día de San Andrés de cada año, de manera que la ciudad guarde su derecho antiguo, como hasta abora. Asimismo, el último de los capítulos contempló que el Ayuntamiento de Nájera, teniendo en consideración el estado en que se encontrasen dichos montes, podrían hacer las ordenanzas que entendiesen convenir, al objeto de que se tornase a pacer en los dichos montes y a cortar leña en el monte de Matarredo y, en su caso, en las nuevas extensiones forestales.

\section{Ordenanzas de Nájera sobre guarda de los montes}

"Ayuntamiento

En la ciudad de Nájera, a cinco días del mes de octubre, año del señor de mil y quinientos y sesenta años, estando juntos en las casas del consistorio de la dicha ciudad los muy magníficos señores Peña Velázquez, juez de Residencia y Justicia en la dicha ciudad y su jurisdicción, por el Illmo señor el duque de Nájera, mi señor, y Rodrigo Ximénez de Cabredo y Hernando Aguado, regidores, y el doctor Mendoza y el doctor Cañas y Martín de Vergara, Antonio de león, Pero de Rodezno, Gonzalo García, diputados, Sebastián de Vergara, procurador general de la dicha ciudad, según que lo han y tienen de uso y de costumbre de se ajuntar para entender en las cosas tocantes a la dicha ciudad y a la República, en presencia de mí, Juan de Sevilla, escribano del dicho Ayuntamiento, habiendo visto la Provisión real, con la Carta acordada en ella inserta sobre la guarda y conservación de los montes, y la información por virtud de ella tomada de la tala y destrucción del monte de Matarredo de la dicha ciudad, de que en la Provisión se hace mención, dijeron que, atenta la dicha información y el tenor de la dicha Provisión, para hacer las ordenanzas de que en la Provisión real se hace mención, que fuesen llamados Alonso Rubio y Alonso de Yanguas, el doctor Juan Alonso, Pero Hernández de Nieva, Pero de Cerezo, Diego de Logroño, Diego Pérez de Calahorra, Sancho Marín, Juan de Solano, Iñigo Cordero el viejo, Fernando de Hontaneda, Diego de Páganos, Hernán López, vecinos de la dicha ciudad, personas hábiles y de buen entendimiento y de los que tienen experiencia de las cosas de la dicha ciudad y republica de ella, para que todos juntos vean y confieran y ordenan la orden y forma que mejor sea para poder hacer que se guarde y conserve el dicho monte y los que se plantaren de nuevo. Y se hagan para ello las ordenanzas necesarias, como por la Majestad real es mandado. 
Y así lo acordaron y firmaron Peña Velázquez, Rodrigo Ximénez de Cabredo, Hernando Aguado, doctor Mendoza, el doctor Cañas, Martínjn de Vergara, Pedro de Rodezno, Sebastián Vergara.

Y después de lo susodicho, a veinte días del mes de octubre del dicho año de mil y quinientos y sesenta años, estando juntos en las casas del dicho consistorio, los dichos señores Justicia y Regimiento, juntamente con los dichos Alonso Rubio, el doctor Juan Alonso y las otras personas arriba nombradas para hacer y ordenar las ordenanzas que convengan para que el dicho monte de Matarredo se guarde y conserve y pueble, por haber falta de monte; y para que se plante y críe otro de nuevo, todos juntos, como nombrados, son unánimes y conformes, después de bien haber platicado y conferido la forma y manera que se había de tener para la dicha guarda y conservación del dicho monte de Matarredo y la plantía que se había de hacer de nuevo para otro monte en el término de la Rad y Verde de que en la Provisión e Información se hace mención. Vista la dicha información y como ellos por vista de ojos dijeron haber visto el dicho monte de Matarredo y término, les pareció a todos juntos que se habían de hacer y ordenar y ordenaron las ordenanzas siguientes:

Primeramente, ordenaron y mandaron, vista la gran destrucción y tala del dicho monte de Matarredo y la mucha necesidad que hay de la guarda y conservación, y que, aunque está atalado, quedaron raíces en él para que, dándose forma que no se corte ni saque de cuajo de aquí adelante y se planten las manchas grandes que no hay árboles, de aquí adelante podrá tornarse a poblar cómo antes estaba. Por ende que debían de mandar y mandaban y ordenaban que ninguna persona, vecino de esta ciudad, ni estante en ella, ni de fuera parte de ella, no pueda cortar, ni corte por pie ni por rama ni saque de cuajo en el dicho monte de Matarredo, so pena de cualquier persona que pareciere haber cortado en el dicho monte por pie alguna encina grande o pequeña, caiga e incurra ipso facto en mil maravedíes de pena; y el que pareciera haber cortado por rama, caiga e incurra en pena de quinientos maravedíes; y el que pareciere haber sacado raíces de cuajo, que incurra y caiga en la dicha pena del que cortare por píe. En las cuales penas, desde luego, lo hemos por condenado a cualquier persona que lo contrario hiciere, para que se pueda ejecutar en sus personas y bienes.

Otrosí, ordenaron que, porque el dicho monte de Matarredo sea mejor guardado y todos tengan temor de entrar a cortar en él, que, por la primera vez que se hallare haber cortado o sacado de cuajo según dicho es, caiga e incurra en la dicha pena arriba dicha de día y si fuere de noche, la dicha pena doblada; y por la segunda vez incurra en la dicha pena doblada; y por la tercera y rebeldía pague la dicha pena doblada ésté dos la cáreet. En las cuales penas, desde ahora, los damos por condenados y aplicamos las dichas penas, la mitad para la bolsa de la ciudad y la otra mitad en dos partes, la una para el denunciador y la otra para el juez que lo sentenciare.

Iten, ordenaron y mandaron que, atento que en el dicho monte de Matarredo, por haber habido tanta tala y destrucción, está en muchas partes despoblado de árboles y sacado de cuajo tanta cantidad que no se podría tornar a poblar si no se sembrase de encina, por ende que ordenaban y mandaban que, todas las dichas partes que así está despoblado en el dicho monte y sacado de cuajo, se rompan, aren y siembren de encina de bellota, para que se torne a poblar como lo demás del dicho monte, porque así convenía al provecho y utilidad de toda esta comarca y para abrigo de los ganados; y porque para haberse de poblar, si no se guardase el paso no habría remedio, ordenaron y mandaron que ningún vecino de la dicha ciudad, ni de fuera parte, ahora, tengo derecho de pacer en él o no lo tenga, no puedan entrar a pacer con sus ganados mayores ni menores, de día ni de noche, que el dicho monte por espacio de diez años después que así se plantare de manera que lo que así se plantare de nuevo en el dicho monte esté criado, so pena que cualquiera que entrare en el dicho monte a pacer 
con cualquier ganado rebaño, caiga e incurra en pena de mil maravedís por rebaño y más el daño y de noche la pena doblada. Ysi fuere en rebeldía la dicha pena y tádo a la vergüenza públicamente por las calles públicas de entad ${ }^{36}$; y si fueren cabras la pena doblada; y entiendese rebaño, diez cabezas menores; y de ahí abajo, un real de pena de cada cabeza, si fuere ganado mayor, por cada cabeza cuatro reales de día, y de noche la dicha pena doblada; y se pueda hacer información sobre ello; y aplicaron las dichas penas según dicho es.

Otrosí ordenaron que atento que la ciudad tiene derecho de cada año que hubiere en el dicho monte de Matarredo de arrendar y xericar el pasto y finy desde el día de San Miguel de setiembre hasta el día de San Andrés de cada año, que se entienda que el pasto no lo pueda arrendar durante el dicho tiempo de los dichos diez años, más de solamente la finy y esta que la puedan sacar y coger de tal manera que no se pazca con ganados dentro del dicho monte, porque así conviene para que el dicho monte se torne a poblar y pasados los diez años la ciudad guarde su derecho antiguo como hasta ahora.

Otrosí ordenaron que atento como por vista de ojos e información que sobre el caso está tomado parece había necesidad de aumentar los montes y plantarlos y criarlos de nuevo, pues había sobra de pasto y falta de montes para la utilidad y provecho de los vecinos de la dicha ciudad y de los que tienen derecho de pacer en los términos de la Rad y Verde y como está averiguado que el dicho término es más de veinte y cinco mil fanegas de tierra por lo haber paseado y andado y medido para otros efectos, y más de las veinte y tres mil fanegas están por romper, que, para que haya más montes, debían de ordenar y mandar y ordenaron que se siembre de bellota y haya en el dicho término de la Verde, hasta en cantidad de mil y ochocientas fanegas de tierra, poco más o menos, y siembre de bellota comenzando del quebrado de Taunconegro, hasta la Vengatilla; y de allí la Rbba, Gallinero, Aldaillana hasta dar en el término de Cenicero y bajara de la llana a Valdesalamón, y llegar al camino que van los de Cenicero a Somalo, afrontar con las piezas labradas de la Riba y Valdesalamón, volviendo el dicho camino a dar en las viñas de Cenicero, que es la tierra más aparejada para poderse plantar y criar el dicho monte y para que después de criado tengan abrigo y acogida el ganado en tiempo de fortuna para que después de bien criado puedan cortar leña de él cuando sea tiempo.

Otrosí ordenaron y mandaron que para que el dicho monte, que de nuevo se plantare, se críe mejor, que ninguna persona de la dicha ciudad ni de fuera parte de ella, en dicho término, no puedan entrar a pacer con ganados mayores ni menores de día ni de noche en el dicho monte que así se plantare por espacio de diez años, de manera que el dicho monte esté criado so las penas contenidas en el tercero capítulo de esta ordenanza arriba dicho, en las cuales los damos por condenados lo contrario haciendo y aplicadas según dicho es.

Otrosí ordenaron y mandaron que porque los dichos montes de Matarredo en el que de nuevo se plantare arriba dichos y cualquiera de ellos sean mejor guardados y conservados y las dichas penas se ejecuten y puedan ejecutar contra los que pasaren contra las dichas ordenanzas, o cualquiera de ellas, se pueda hacer información de testigos para que, si las guardas no los vieren al tiempo que hicieren los dichos cortes o entraren a pacer contra las dichas ordenanzas, pudiéndose probar con testigo, sean condenados en las dichas penas como si la guarda los viese y hallase haciendo daño. $\mathrm{Y}$ si la guarda los viere y denunciare a la Justicia, sea creído por su juramento, como uso y costumbre en esta ciudad en otras cosas y prendas que hacen las guardas de ella.

${ }^{36}$ Se ha tachado en el original. 
Otrosí dijeron que pasado el dicho tiempo de la cría d ellos dichos montes, visto por los del ayuntamiento de esta ciudad, que a la sazón fueren, si les pareciere que es tiempo de pacer en los dichos montes y en cualquiera de ellos y cortar leña en el dicho monte de Matarredo en lo que ahora está criado, para solamente pacer y hacer leña, puedan hacer las ordenanzas que convengan de las euales no usen hasta que se al Consejo y se confirmen por Su Majestad. $Y$ hechas las dichas ordenanzas, las envien al Consejo y no usen de ellas hasta que estén confirmadas ${ }^{37}$.

Y así dijeron que lo ordenaban y mandaban por virtud de la dicha Provisión real, y lo mandaron pregonar, y lo firmaron Peña Velázquez, Rodrigo Ximénez de Cabredo, Hernando Aguado, doctor Mendoza, el doctor Cañas, Martín de Vergara, Gonzalo García, Antonio de León, Sebastián Vergara, Pedro de Rodezno, el doctor Arcos, Pero de Cerezo, el doctor Juan Alonso, Fernán Hontaneda, Pero Fernández, Alonso de Yanguas, Pero Cordero, Alonso Rubio, Íñigo Cordero, Sancho Martínez, Diego de Páganos, Bartolomé de Santo Domingo, Diego Pérez de Calahorra, Hernán López. Pasó ante mí, Juan de Sevilla.

Pregón.

E después de lo susodicho, en la dicha ciudad de Nájera, a treinta y un días del mes de octubre del dicho año de mil y quinientos y sesenta años, en la plaza de San Juan, frontero las casas del consistorio de la dicha ciudad, estando presentes los dichos señores Justicia y Ayuntamiento y gran copia de vecinos de la dicha ciudad, pregonaron públicamente las dichas ordenanzas como en ellas se contiene, a altas voces, que todos lo podían oír. Testigos que fueron presentes Pedro de Salazar, vecino de Cenicero y Pero Escudero, escribano, y Fernán García y otros muchos vecinos de la dicha ciudad y de fuera parte de ella, e lo firmé. Pasó ante mí, Juan de Sevilla.

Y yo, el dicho Juan de Sevilla, escribano público de la Majestad Real y del número de la dicha ciudad de Nájera, que a todo lo que dicho es quede mí se hace mención presente fui en uno con los dichos testigos. Lo susodicho hice escribir y escribí según pasó ante mí. Que va escrito en estas veinte hojas de medio pliego de papel e hice aquí este mi signo en testimonio de verdad. Juan de Sevilla".

${ }^{37}$ Se ha insertado en el margen en el original, como resultado de la intervención del Consejo en la confirmación de las Ordenanzas. 